\title{
QUATERNÁRIO: CIENCIOMETRIA E MAPEAMENTO DOS ESTUDOS PALINOLÓGICOS DO BIOMA CERRADO E IMPORTÂNCIA PARA ARQUEOLOGIA
}

Resumo: As mudanças do Cerrado ao longo do tempo, influenciadas por fatores antrópicos, naturais ou por mudanças climáticas, são determinantes na disposição da paisagem. A palinologia de sedimentos do Quaternário permite a reconstituição do paleoambiente onde viveu o homem pré-histórico. O objetivo foi realizar análise quantitativa da distribuição temporal e regional de estudos acerca da palinologia do Cerrado. A cienciometria demonstra a evolução da produção científica sobre palinologia do Pleistoceno superior e Holoceno, permitindo identificar lacunas. Foram analisados quantitativamente 48 estudos palinológicos com publicações descontínuas entre 1987 e 2016, ocorrendo os maiores números de publicação em 1993. As modificações fitofisionômicas do Cerrado ao longo do Quaternário não são iguais, homogêneas e sincrônicas para todas as áreas de sítio arqueológico no bioma.

Palavras-chave: Palinologia. Paleoambiente. Geopalinologia. Ciência Ambiental.

\section{QUARTERNARY: SCIENCIOMETRY AND MAPPING OF PALINOLOGICAL STUDIES OF THE CERRADO BIOME AND IMPORTANCE TO ARCHEOLOGY}

Abstract: The Cerrado's changes over time, influenced by anthropic, natural or climatic changes, are determinant in the landscape layout. The palynology of Quaternary sediments constitutes a source of data which allows the reconstruction of the paleoenvironment where the prehistoric man lived. The objective was to make a quantitative analysis of the temporal and regional distribution of studies about the Cerrado's Palinology. Scientometry demonstrates the scientific production's evolution on the Upper Pleistocene and Holocene palynology, allowing to identify gaps in the studies. A total of 48 studies were quantitatively studied with discontinuous publications between 1987 and 2016, presenting the best publication numbers in 1993. The Cerrado's phytophysiognomic modifications along the Quaternary aren't homogeneous and synchronous for all areas of archaeological site in the biome.

Keywords: Palynology. Paleoenvironment. Geopalynology. Environmental Science.

\section{CUATERNARIO: CIENCIOMETRÍA Y MAPEO DE ESTUDIOS PALINOLÓGICOS DEL BIOMA CERRADO E IMPORTANCIA PARA LA ARQUEOLOGÍA}

Resumen: Los cambios del Cerrado a lo largo del tiempo, influenciados por factores antrópicos, naturales o por cambios climáticos, son determinantes en la disposición del paisaje. La palinología de sedimentos del Cuaternario permite la reconstitución del paleoambiente donde vivió el hombre prehistórico. El objetivo fue realizar análisis cuantitativo de la distribución temporal y regional de estudios acerca de la

\footnotetext{
${ }^{1}$ Instituto Federal de Educação Ciência e Tecnologia de Goiás, Departamento de Meio Ambiente, Goiânia, Brasil, carol.mirannda@gmail.com, https://orcid.org/0000-0002-1825-0097

${ }^{2}$ Instituto Federal de Educação Ciência e Tecnologia de Goiás, Goiânia, Brasil, gabrielapaolasilva@yahoo.com.br, https://orcid.org/0000-0002-1825-0097
} 
palinología del Cerrado. La cienciometría demuestra la evolución de la producción científica sobre la palinología del Pleistoceno superior y el Holoceno, permitiendo identificar carencias. Se analizaron cuantitativamente 48 estudios palinológicos con publicaciones discontinuas entre 1987 y 2016, ocurriendo los mayores números de publicación en 1993. Las modificaciones fitofisiómicas del Cerrado a lo largo del Cuaternario no son iguales, homogéneas y sincrónicas para todas las áreas de sitio arqueológico en el bioma.

Palabras clave: Palinología. Paleoambiente. Geopalinología. Ciencia Ambiental.

\section{Introdução}

Com o advento da domesticação das plantas e dos animais, iniciaram-se as atividades de agricultura. De acordo com Neves (1995, 2015), uma das maiores contribuições dos índios americanos para outras populações foi o grande número de plantas domesticadas durante o período pré-colonial (tomate, batata, tabaco, milho, pimenta, amendoim, mandioca, abacaxi, mamão, maracujá, abóbora, coca, batata doce, feijão, algodão, pupunha, açaí, urucum e outras).

Segundo Tassinari (1995), na prática da coivara por povos indígenas devese considerar que os territórios queimados para plantações de pequena escala são de pequena extensão e com rodízio do solo ocupado, fornecendo condições para a mata se reestabelecer e garantindo nutrientes ao solo. Consiste na derrubada, ressecamento e posterior queima controlada da mata (NEVES, 1995; SILVA, 2009).

É através do estudo dessas paisagens que, mesmo transformadas no presente, a arqueologia pode contribuir para o entendimento do passado brasileiro (NEVES, 1995). Salgado-Labouriau (1984) ressalta que o conhecimento da vegetação do passado, assim como das sucessões e mudanças provocadas por modificações no meio físico são importantes para o entendimento dos mecanismos responsáveis pelo surgimento e manutenção da biodiversidade, fornecendo modelos adequados de conservação e manejo dos ecossistemas contemporâneos.

\section{Cienciometria}

Por definição, cienciometria é o estudo dos aspectos quantitativos das atividades científicas envolvendo estudos de publicações; sendo um segmento da sociologia da ciência, e aplicada no desenvolvimento de políticas científicas (MACIAS-CHAPULA, 1998).

A abordagem quantitativa da produção científica é um elemento indispensável no processo de investigação da produção do conhecimento, constituindo-se como 
uma ferramenta para a gestão das políticas científicas e tecnológicas (ARENCIBIA; DE MOYA, 2008).

Para Mingers e Leydesdorff (2015) a cienciometria pode ser considerada como um processo da comunicação que se fundamenta no estudo de aspectos quantitativos da ciência e tecnologia. A cienciometria, portanto, pode ser aplicada no gerenciamento das informações originárias de bases de dados científicas permitindo identificar tendências e o crescimento do conhecimento de determinadas áreas (VANTI, 2002).

Nesse contexto, a cienciometria possibilita compreender a evolução da produção científica estabelecendo relações entre ciência e tecnologia (SPINAK, 1998), por meio da utilização de indicadores quantitativos para avaliar a qualidade da produção científica.

O estudo cienciométrico permite estabelecer relações entre o crescimento quantitativo da pesquisa e as lacunas existentes, além de verificar as contribuições e tendências de uma determinada disciplina para o desenvolvimento de políticas científicas (MACIAS-CHAPULA, 1998; STREHL; SANTOS, 2002).

\section{Geologia Histórica X Estudos Paleoambientais}

A forma como entendemos e calculamos o tempo cultural presente não é equiparável ao tempo geológico - o tempo profundo. Assim, para melhor compreender este tempo geológico, através de registros dos fenômenos naturais a ele vinculados e a estratigrafia das rochas, convencionou-se as chamadas eras geológicas (TOLEDO, 2009).

Esta pesquisa atém-se à era Cenozóica - aplicando seus esforços no período Quaternário, quando se dá a evolução da humanidade, desde os primeiros hominídeos no continente africano (NEVES, 1995) até a migração do Homo sapiens sapiens para a América (11.500 anos) (MARTíNEZ, 2007; PROUS, 1997) e que compreende também as oscilações climáticas conhecidas como glaciações quaternárias.

A vegetação não se altera radicalmente na pré-história antiga, a não ser por razões climáticas e ambientais. Portanto, o estudo da Pré-História, no que se concerne a paleovegetação, privilegia a vertente natural do desenvolvimento e evolução da cobertura vegetal, uma vez que alguns tipos polínicos são bons indicadores climáticos, permitindo a reconstrução paleoecológica (BICHO, 2006). 
A Paleoecologia é a ciência que, através da Palinologia, estuda a deposição polínica ao longo do tempo geológico, reconstruindo ambientes pretéritos por meio do pólen das Angiospermas e Gimnospermas e esporos fósseis das Pteridófitas, permitindo a caracterização das variações da vegetação e consequentemente do clima do passado (SALGADO-LABOURIAU, 1973; CASSINO, 2014).

De acordo com Salgado-Labouriau (1984), os palinomorfos constituem uma das principais fontes para a reconstrução de paleoambientes. O método paleobotânico mais importante para a reconstrução paleoecológica em arqueologia pré-histórica tem sido a palinologia (BICHO, 2006).

A palinologia, estudo do pólen, teve início em 1916 (SALGADO-LABOURIAU, 1973). Segundo Bicho (2006), o exame polínico deve ser feito com microscópio óptico de qualidade e o estudo da paleovegetação torna-se possível devido aos grãos de pólen de algumas espécies apresentarem exina resistente e elástica, que permite a preservação do pólen em sedimentos e consequentemente a identificação. $O$ autor ressalta ainda que a melhor preservação do pólen se dá em ambientes ácidos e anaeróbios. A quantificação dos grãos de pólen, procedimento lento e de precisão, permite a reconstrução paleoecológica local e regional (CASSINO, 2014), geralmente apresentada por meio de diagramas polínicos. Os diagramas mostram curvas de frequência relativa de cada espécie vegetal ao longo de um eixo correspondente à cronologia da sequência deposicional de onde foram amostrados os pólen (BICHO, 2006). Assim, a palinologia permite o estudo das mudanças fitofisionomicas e, paralelamente, do clima no decorrer do tempo (ABSY et al., 1993; BEHLING, 1998; BICHO, 2006; CASSINO, 2014; SALGADO-LABOURIAU, 1984; LORENTE et al., 2010).

\section{A Importância das Mudanças Climáticas e da Palinologia para a Arqueologia Pré-Histórica}

A importância do estudo do clima e dos estudos palinológicos do período Quaternário está atrelada ao clima futuro, às mudanças geográficas, independentemente da ação antrópica, e ao processo evolutivo do homem, uma vez que o espaço é um dos elementos mais determinantes na evolução cultural humana e também na evolução física da espécie, através da adaptação biológica e cultural (BICHO, 2006; BRAIDWOOD, 1985). Segundo Martínez (2007), as mudanças climáticas no período cultural Mesolítico significaram mudanças na tecnologia (dominada por arcos e flechas). Um exemplo de modificação dos recursos vegetais 
em decorrência das mudanças climáticas foi observado no Saara, onde toda a extensão de areia estéril e pedras se cobriu de árvores e ervas típicas hoje da savana (MARTíNEZ, 2007). Ainda de acordo com Martínez (2007), existem poucas dúvidas de que, em geral, a vida nômade de caçadores-coletores é causada pela mudança e sazonalidade de recursos.

$\mathrm{Na}$ arqueologia se pretende o estudo de vestígios de grupos humanos pretéritos, em paredões, lajes, superfície, solo ou em meio aquático, e suas relações com a biota, os lugares, o espaço físico, a paisagem, entre outras perspectivas que abrangem a flora e seus recursos, sejam eles alimentícios, artísticos, medicinais, simbólicos, cosmológicos, míticos, ritualísticos, culturais ou tecnológicos (NEVES, 1995, 2015; VITA-FINZI; HIGGS, 1970; SCHMITZ, 1999; PROUS, 1992; PIMENTA, 2004; TASSINARI, 1995; SILVA, 1992; MELATTI, 2007).

Segundo Neves (1995), em uma das hipóteses de ocupação das Américas, o Homo sapiens sapiens teria adentrado o continente pelo Estreito de Bering (BRAIDWOOD, 1985) devido à regressão do nível do mar (GOWLETT, 2007) provocada pela contenção da água em forma de gelo nas calotas polares e sobre os continentes (MELATTI, 2007), emergindo assim, uma ligação contínua de terra entre a Sibéria e o Alaska. Por volta de 50.000 anos AP (antes do presente) o nível do mar baixou por volta de $60 \mathrm{~m}$ e há 20.000 anos AP, 90 m (FAGAN, 1987 apud NEVES, 1995). Bartlett et al. (1969) ressalta que durante as migrações humanas préhistóricas, espécies vegetais foram introduzidas antropicamente por meio da agricultura, em biomas onde inicialmente não ocorriam tais espécies.

No Quaternário, as terras baixas tropicais, que compreendem áreas de ocorrência da Amazônia, do Cerrado e da Caatinga, não foram cobertas por geleiras, mas segundo Melatti (2007), foram afetadas por fenômenos relacionados (queda de temperatura, modificação do regime de chuvas, recuo da floresta equatorial, baixa no nível do oceano), afetando a composição e distribuição da vegetação (DO CARMO, 2003). Assim, as glaciações pleistocênicas tiveram uma influência expressiva na evolução dos biomas brasileiros e, consequentemente, nas paisagens, fauna e fitofisionomias do bioma Cerrado (CASSINO, 2014; LORENTE et al., 2010).

De acordo com Martínez (2007), o Holoceno trata-se de um período interglacial que interrompe a grande série de etapas gélidas pleistocênicas. Segundo Neves (1995), o Holoceno tem sido caracterizado por uma estabilidade climática maior que o Pleistoceno, mas ocorreram variações climáticas que provocaram 
mudanças ecológicas temporárias em regiões do atual território brasileiro. De acordo com Van der Hammen (1991), as oscilações climáticas do Holoceno provocaram diferenciações regionais, influenciando a distribuição da presente vegetação (CASSINO; MEYER, 2013).

Neves (1995) ressalta que provavelmente parte do arsenal de caça era composto por madeira, não se preservando no registro arqueológico tropical e subtropical (GOWLETT, 2007), salvo em condições ideais. Pinturas rupestres muitas vezes representam pessoas em atitudes de caça, com arco-e-flecha (BRAIDWOOD, 1985). De acordo com Neves (1995), a megafauna, representada, entre outros, pelos megatérios (preguiças gigantes) e gliptodontes (tatus gigantes) foi extinta no Brasil (MELATTI, 2007), com isso as atividades de coleta tornaram-se de importância ainda maior.

Seguindo a mesma linha de raciocínio, os demais recursos vegetais utilizados por populações pré-históricas também não se conservam em condições não ideais do registro arqueológico.

Entre os recursos naturais, a madeira constitui uma das matérias-primas mais utilizadas pelo homem. Sua importância para a produção de manufaturas indispensáveis à vida cotidiana não foi inferior ao uso da pedra: muitos utensílios foram feitos de madeira; igualmente muitas construções ou parte delas; objetos móveis, como recipientes com diversas funções e dimensões. Também utilizada como matéria-prima para confecção de objetos artísticos, entre os quais se destacam as esculturas (MANNONI; GUIANNICHEDDA, 2007). Entretanto, deve-se recordar que a disponibilidade do recurso vegetal no meio ambiente não implica diretamente em sua coleta e uso por sociedades humanas, pois cada povo estabelece seus critérios de relação com a natureza (TASSINARI, 1995).

Neste sentido, Miller (2009) ressalta que estudos ecológicos realizados por etnógrafos tem se mostrado valiosos para a arqueologia, direta ou indiretamente.

Em sítios arqueológicos com boas condições de preservação (grutas calcárias da região de Lagoa Santa-MG e do norte de Minas Gerais, sambaquis e sítios a céu aberto do agreste nordestino), existe um número significativo de plantas consumidas (NEVES, 1995), como na Lapa do Gentio em Minas Gerais onde foram descobertas quatro espécies de milho datando de 2.000 a.C. (antes de Cristo), amendoim, cabaça e abóbora (MELATTI, 2007). Segundo Gowlett (2007), a presença de sementes pode determinar a estação do ano e, por vezes, o mês em que foram coletadas. 
Alguns artefatos cerâmicos que se conservam no registro arqueológico, espelham indiretamente através de suas formas, os alimentos vegetais que ali eram armazenados, como pratos assadores, usados na fabricação de farinha de mandioca e cuscuzeiros indicando o consumo de milho (MELATTI, 2007). No entanto, os dados sobre a vegetação através destes artefatos deixam a desejar, pois a palinologia resulta em dados mais representativos neste sentido.

O conhecimento do paleoambiente permite inserir a contextualização precisa do homem, portanto, busca-se a reconstituição do meio ambiente (PROUS, 1992; $\mathrm{BICHO}, 2006)$.

Assim, torna-se de suma importância para a arqueologia conhecer os estudos prévios de palinologia que evidenciam mudanças constantes no clima e na vegetação no decorrer do Quaternário em áreas relacionadas à captação de recursos, ao uso e à ocupação por populações humanas. Os distúrbios antrópicos na paleovegetação nativa (ocasionados pela agricultura) também podem ser identificáveis por meio da palinologia, além da identificação de alimentos e plantas medicinais consumidas por populações pré-históricas com base em análises palinológicas de coprólitos (fezes fossilizadas) (RIBEIRO; BARBERI, 2005; DE MIRANDA CHAVES, 2000).

\section{Conjuntos Polínicos Contemporâneos do Cerrado em Reconstruções Paleobotânicas}

Bicho (2006) aponta que um aspecto importante no estudo da paleobotânica é a construção e desenvolvimento de coleções de pólen do bioma contemporâneo, para que possam ser realizadas correlações comparativas entre a paleovegetação e os táxons da presente flora, uma vez que, desde o início do Pleistoceno, a paleovegetação é semelhante à flora contemporânea (LORENTE; MEYER, 2010).

Cassino et al. (2016) demonstra que alguns tipos polínicos ocorrem mutuamente em fitofisionomias diferentes, mas conclui que é possível diferenciar os conjuntos polínicos das diversas fitofisionomias do Cerrado. Gosling et al. (2009) demonstram que alguns táxons polínicos podem ser considerados diagnósticos de uma fitofisionomia, sendo o Cerrado Sentido Restrito reconhecido pela associação Poaceae com tipo Machaerium (= tipo Byrsonima), Myrtaceae, Borreria e/ou Solanum; o Cerrado Típico (SALGADO-LABOURIAU, 1973) reconhecido pelas famílias: Poaceae e leguminosas (Fabaceae), podendo ocorrer também Myrtaceae, 
Borreria, Solanaceae e Malpighiaceae; o Cerrado, de maneira geral (LEDRU, 2002), representado por: Byrsonima e Didymopanax (Schefflera), Caryocar e Qualea; são indicativos de Matas de Galeria: Hyeronima, Symplocos e Stigmaphyllon, associados a uma baixa porcentagem de Poaceae (CASSINO et al., 2016); indicativos de Veredas: Mauritia flexuosa geralmente associada a altas concentrações de Poaceae, Cyperaceae, Melastomataceae e Cuphea (CASSINO et al., 2016).

Salgado-Labouriau (1973) pontua que apesar da extensão e importância do bioma Cerrado, existem poucos estudos sobre caracterização sistemática dos grãos de pólen do bioma. Cassino (2014) também ressalta que são raros os trabalhos que visam quantificar a relação entre as fitofisionomias e os conjuntos polínicos contemporâneos, bem como são raros os estudos que utilizam os conjuntos polínicos contemporâneos do bioma para identificar análogos modernos para registros fósseis.

Neste sentido, Cassino (2014) constrói a partir de amostras superficiais, um importante banco de dados de espectros polínicos contemporâneos do Cerrado do norte de Minas Gerais, com 236 tipos polínicos que foram utilizados para a comparação com conjuntos polínicos fósseis, facilitando a identificação e, posteriormente, Cassino (2014) propôs um modelo gráfico de evolução quaternária da paleovegetação e consequentemente do paleoclima do bioma no noroeste de Minas Gerais.

Ainda assim, é importante ressaltar que Cassino (2014) concluiu que para a determinação mais precisa da vegetação regional é necessária uma base de dados de conjuntos polínicos contemporâneos maior e que abranja também amostras coletadas em outros biomas, pois, como exemplo, ao longo do período estudado no Parque Estadual do Rio Doce (10.655 anos A.P - 51 anos A.P) por Da Silva et al. (2013), descobriu-se que a vegetação regional teve modificações de Savana para Mata Atlântica.

O trabalho anterior de Cassino e Meyer (2013) também trás um modelo gráfico de evolução do bioma no quaternário, desta vez no Chapadão dos Gerais, também no estado de Minas Gerais. O mesmo poderá ser feito nos demais estados brasileiros de ocorrência do bioma, pois, por intermédio de análises palinológicas de amostras coletadas em sedimentos do Quaternário e comparação com conjuntos polínicos contemporâneos, é possível a remontagem de cenários pré-históricos. 


\section{Materiais e Métodos}

A análise de conteúdo é uma metodologia de pesquisa utilizada para descrever e interpretar conteúdos de todas as classes de documentos e textos (MORAES, 1999). De acordo com o autor, essa análise, conduzindo descrições sistemáticas, qualitativas ou quantitativas, auxilia na reinterpretação de mensagens e na compreensão dos significados além de uma leitura comum. O autor ressalta que a análise deve envolver a organização de tabelas e quadros. Esta metodologia de análise atinge novas e desafiadoras possibilidades na medida em que se integra na exploração qualitativa de mensagens e informações (MORAES, 1999).

A análise de conteúdo como método de investigação compreende procedimentos específicos para o processamento de dados científicos (MORAES, 1999). De acordo com o autor é um guia prático para a ação, sempre renovado em função dos problemas cada vez mais diversificados.

A metodologia consiste em realizar uma análise de conteúdo baseado em Moraes (1999), de forma quantitativa da distribuição temporal e regional dos artigos, dissertações e teses brasileiras publicadas acerca da palinologia do Quaternário no bioma Cerrado, fazendo também uso de análise cienciométrica.

Portanto, esta pesquisa tem como base estudos palinológicos publicados por diversos autores, como artigos, teses e dissertações na área de estudo e que podem potencialmente permitir a reconstituição da dinâmica da vegetação do Cerrado do Quaternário e que serão organizados e apresentados na forma de gráficos, tabelas, quadros e mapas elaborados com ferramentas de geoprocessamento.

As buscas realizadas em julho de 2016 deverão abranger o período Quaternário em suas subdivisões Pleistoceno superior e Holoceno, ou seja, desde o início do Pleistoceno superior (126.000 mil A.P.) até a contemporaneidade.

\section{Cadastramento de Dados Prévios/Criação de Banco de Dados}

Sob uma abordagem cienciométrica, foi realizado o levantamento de artigos, teses e dissertações disponíveis na base de dados da Coordenação de Aperfeiçoamento de Pessoal de Nível Superior (CAPES), da Associação Brasileira de Estudos do Quaternário (ABEQUA), na Revista Geonomos da Universidade Federal de Minas Gerais (UFMG), no repositório da Universidade de Brasília (UNB) e no sistema integrado da Universidade de São Paulo (USP). 
O levantamento bibliográfico foi realizado em bancos de periódicos, artigos, teses e dissertações utilizando-se as palavras-chaves vinculadas ao tema "Cerrado": "pólen”, "paleovegetação", "palinologia”, "paleobotânica”, "paleopadrão de vegetação", "paleoambiente", "geopalinologia", "paleoclima”, "morfologia polínica", "Holoceno", "Pleistoceno", "paleoecologia", "análise palinológica", "paleoclimatologia". Os resultados da busca foram ainda filtrados para o período Quaternário (Pleistoceno superior - Holoceno).

A categorização é o procedimento de agrupar dados considerando a parte comum entre eles, deve ser entendida como um processo de redução de informações que representa o resultado de um esforço de síntese, destacando aspectos mais importantes (MORAES, 1999). Neste sentido, de posse do material bibliográfico coletado em julho de 2016, foram realizados fichamentos para a melhor disposição das informações. Estes fichamentos compõem o banco de dados da pesquisa e para isso foram categorizados na forma de tabela no programa Microsoft Excel 2010, sendo as colunas principais: "nome do autor", "ano de publicação", "instituição de pesquisa", "título do trabalho", "coordenadas do local de estudo", "faixa temporal", "objetivos" e "conclusões". A categorização possibilitou a produção de gráficos, tabelas, quadros e mapas para verificação do comportamento das publicações e dos estudos no decorrer dos anos.

Outras informações que compõe o banco de dados dizem respeito ao material necessário à elaboração dos mapas, as "shapefiles" de arquivos vetoriais. As shapefiles com informações temáticas contemporâneas dos biomas brasileiros, limite dos estados brasileiros, classificação climática de Köppen para o Brasil e regiões hidrográficas brasileiras foram obtidas em sites governamentais como o site da Agência Nacional de Águas (ANA), Ministério do Meio Ambiente (MMA) e Instituto Brasileiro de Geografia e Estatística (IBGE).

\section{Geoprocessamento}

Com base nas informações expostas no banco de dados da pesquisa, foram elaborados mapeamentos temáticos georreferenciados dos locais de amostragem palinológicas do Quaternário, publicados por diversos autores no bioma Cerrado.

Para este fim foi utilizado o laboratório de informática da PUC-GO, localizado na cidade de Goiânia-GO. 
Estes mapeamentos temáticos permitiram análises cienciométricas por meio de gráficos elaborados no programa Microsoft Excel 2010. Para elaboração dos mapas se fez uso dos programas:

- GPS TrackMaker: configurou-se o programa no sistema de coordenadas geográficas, datum Sirgas 2000. Com a ferramenta "lápis" lançaram-se as coordenadas de latitude e longitude de cada local amostrado. Por fim, salvou-se o arquivo dos pontos em formato shapefile;

- ArcGis 10.3: configurou-se o programa no sistema de coordenadas geográficas, datum Sirgas 2000. Adicionou-se a shapefile dos pontos amostrados e a sobrepuséramos com shapefiles temáticas (disponíveis no banco de dados da pesquisa), deste modo, elaboraram-se os mapas temáticos.

\section{Resultados e Discussões}

Foram encontrados um total de 11 estudos sobre palinologia do Quaternário no bioma Cerrado (GARCIA, 1994; BARBERI, 2001; RIBEIRO et al., 2003; DO CARMO et al., 2003; LORENTE et al., 2010; LORENTE; MEYER, 2010; FONTES et al., 2011; CASSINO; MEYER, 2013; DA SILVA et al., 2013; CASSINO, 2014; CASSINO et al., 2016) que tiveram seus conteúdos analisados quantitativamente.

\section{Análise Quantitativa}

Outros 37 trabalhos realizados por diversos autores a respeito da palinologia do Quaternário no bioma Cerrado são mencionados por Garcia (1994), Lorente et al. (2010), Cassino e Meyer (2013) e Cassino (2014). Estes 37 estudos somados aos resultados da busca (11) totalizaram então, 48 estudos.

Os 48 estudos foram publicados entre os anos de 1987 e 2016 (intervalo de 29 anos), porém, dentro deste intervalo de tempo, os anos de 1988, 2004, 2005, 2007, 2008 e 2015 não revelaram nenhuma publicação de estudo palinológico.

A maior produção aconteceu em 1993, com oito publicações. A Figura 1 demonstra que existem poucos estudos palinológicos publicados no Cerrado e de forma descontínua. 


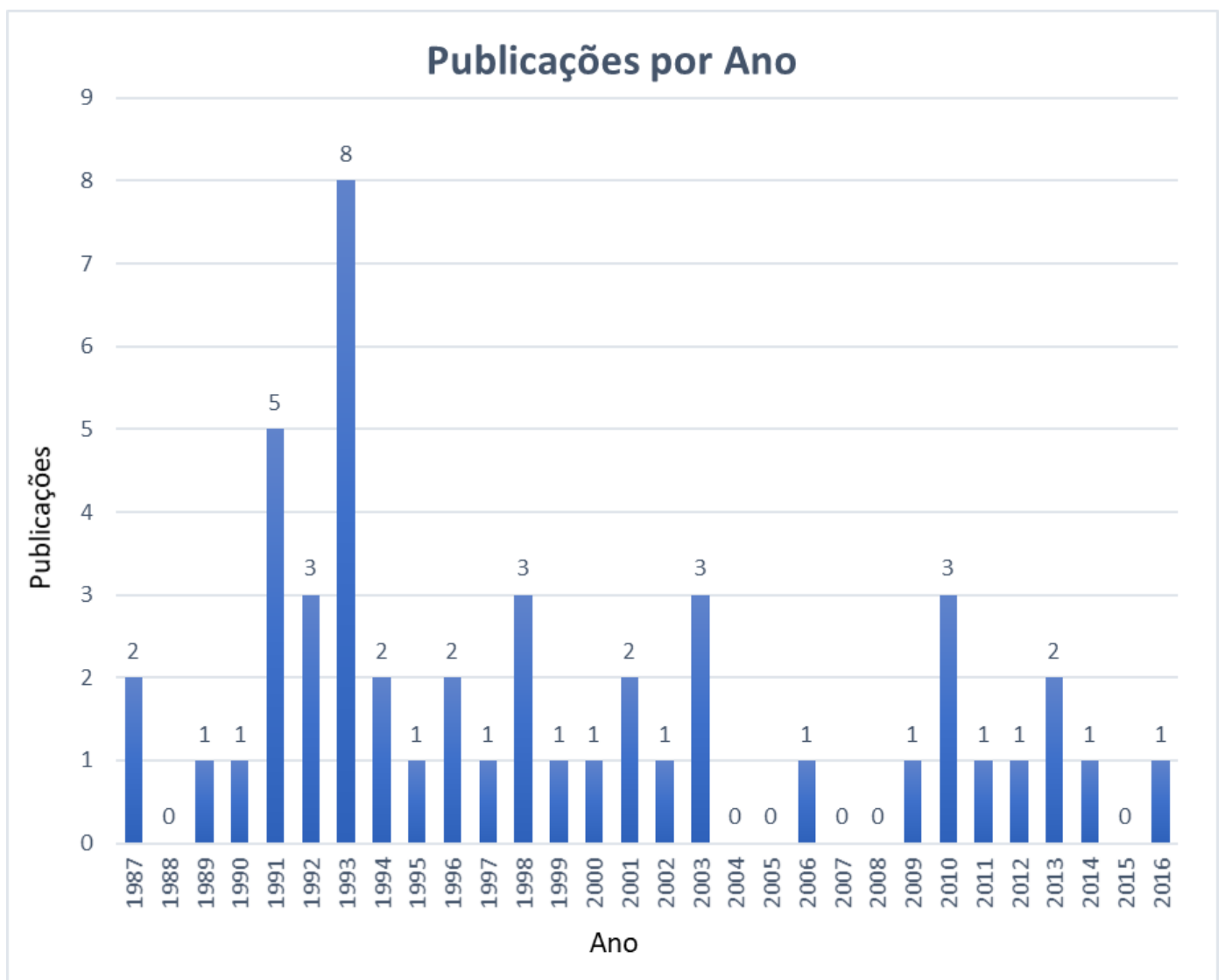

Figura 1: Total de publicações por ano.

A oscilação e descontinuidade de publicações sugere que maiores esforços de incentivo à pesquisa necessitam ser realizados na área da educação brasileira (ciência e pesquisa), especialmente em instituições que realizam estudos palinológicos, de modo que novas pesquisas possam ser publicadas e com maior frequência.

A elaboração do fichamento e análise de conteúdo dos 11 estudos obtidos nas buscas, conforme disposto na metodologia (GARCIA, 1994; BARBERI, 2001; RIBEIRO et al., 2003; DO CARMO et al., 2003; LORENTE et al., 2010; LORENTE; MEYER, 2010; FONTES et al., 2011; CASSINO; MEYER, 2013; DA SILVA et al., 2013; CASSINO, 2014; CASSINO et al., 2016), permitiu a plotagem no software GPS TrackMaker de apenas 22 pares de coordenadas de locais estudados por Ferraz-Vicentini (1993); Barberi (1994); Garcia (1994); Ferraz-Vicentini; SalgadoLabouriau (1996); Ledru et al. (1996); Salgado-Labouriau et al. (1997); SalgadoLabouriau et al. (1998); Barberi (1998); Parizzi et al. (1998); Ferraz-Vicentini (1999); Barberi et al. (2000); Barberi (2001); Ribeiro et al. (2003); Do Carmo et al. (2003); Horák (2009); Lorente et al. (2010); Lorente; Meyer (2010); Fontes et al. (2011); Cassino; Meyer (2013); Da Silva et al. (2013); Cassino (2014); Cassino et al. (2016) (Tabela 1). 
MIRANDA, SILVA

Tabela 1: Estudos palinológicos no Cerrado.

\begin{tabular}{|c|c|c|c|c|}
\hline Ponto & Localidade-UF & Denominação da Amostra & Coordenadas Geogr & Datum Sirgas 2000 \\
\hline 1 & Buritizeiro-MG & Vereda Laçador & $-17^{\circ} 49^{\prime} 03,59^{\prime \prime}$ & $-45^{\circ} 26^{\prime} 27,79^{\prime \prime}$ \\
\hline 2 & Brasilia-DF & Águas Emendadas & $-15^{\circ} 34^{\prime} 00,00^{\prime \prime}$ & $-47^{\circ} 35^{\prime} 00,00^{\prime \prime}$ \\
\hline 3 & Cromínia-GO & Crominia & $-17^{\circ} 17^{\prime} \infty 0,00^{\prime \prime}$ & $-49^{\circ} 25^{\prime} 00,00^{\prime \prime}$ \\
\hline 4 & Buritizeiro-MG & Vereda Urbano & $-17^{\circ} 24^{\prime} 25,00^{\prime \prime}$ & $-45^{\circ} 03^{\prime} 33,00^{\prime \prime}$ \\
\hline 5 & Água Boa-MG & Lago do Pires & $-17^{\circ} 57^{\prime} 00,00^{\prime \prime}$ & $-42^{\circ} 13^{\prime} 00,00^{\prime \prime}$ \\
\hline 6 & Diamantina-MG & Pau de Fruta & $-18^{\circ} 15^{\prime} 00,00^{\prime \prime}$ & $-43^{\circ} 40^{\circ} 00,00^{\prime \prime}$ \\
\hline 7 & Patrocínio-MG & Lagoa de Serra Negra & $-18^{\circ} 55^{\prime} 00,00^{\prime \prime}$ & $-46^{\circ} 50^{\prime} 00,00^{\prime \prime}$ \\
\hline 8 & Patrocínio-MG & Serra do Salitre & $-19^{\circ} 00^{\prime} 00,00^{\prime \prime}$ & $-46^{\circ} 46^{\prime} 00,00^{\prime \prime}$ \\
\hline 9 & Lagoa Santa-MG & Lagoa Santa & $-19^{\circ} 38^{\prime} 00,00^{\prime \prime}$ & $-43^{\circ} 54^{\prime} 00,00^{\prime \prime}$ \\
\hline 10 & Jacareacanga-PA & Lago do Saci & $-09^{\circ} 07^{\prime} 00,00^{\prime \prime}$ & $-56^{\circ} 16^{\prime} 00,00^{\prime \prime}$ \\
\hline 11 & Buritizeiro-MG & Vereda São José & $-17^{\circ} 04^{\prime} 00,00^{\prime \prime}$ & $-45^{\circ} 06^{\prime} 00,00^{\prime \prime}$ \\
\hline 12 & Primeira Cruz-MA & Lagoa do Caçó & $-02^{\circ} 58^{\prime} 00,00^{\prime \prime}$ & $-43^{\circ} 25^{\prime} 00,00^{\prime \prime}$ \\
\hline 13 & Lagoa da Confusão-TO & Lagoa da Confusão & $-10^{\circ} 38^{\prime} 00,00^{\prime \prime}$ & $-49^{\circ} 43^{\prime} 00,00^{\prime \prime}$ \\
\hline 14 & Água Boa-MG & Lagoa Nova & $-17^{\circ} 58^{\prime} 00,00^{\prime \prime}$ & $-42^{\circ} 12^{\prime \prime} 00,00^{\prime \prime}$ \\
\hline 15 & Lagoa Santa-MG & Lagoa dos Olhos D'água & $-19^{\circ} 39^{\prime} 00,00^{\prime \prime}$ & $-43^{\circ} 49^{\prime \prime} 00,00^{\prime \prime}$ \\
\hline 16 & Jacareí-SP & Jacareí & $-23^{\circ} 15^{\prime} 00,00^{\prime \prime}$ & $-46^{\circ} 00^{\prime} 00,00^{\prime \prime}$ \\
\hline 17 & São José dos Campos-SP & Eugênio de Melo & $-23^{\circ} 10^{\prime} 00,00^{\prime \prime}$ & $-46^{\circ} 20^{\prime} 00,00^{\prime \prime}$ \\
\hline 18 & Taubaté-SP & Taubaté & $-23^{\circ} 00^{\prime} 00,00^{\prime \prime}$ & $-45^{\circ} 45^{\prime} 00,00^{\prime \prime}$ \\
\hline 19 & Brazabrantes-GO & Brazabrantes & $-16^{\circ} 26^{\prime} 10,26^{\prime \prime}$ & $-49^{\circ} 23^{\prime} 28,78^{\prime \prime}$ \\
\hline 20 & Goiânia-GO & Goiânia & $-16^{\circ} 39^{\prime} 46,85^{\prime \prime}$ & $-49^{\circ} 1716,84^{\prime \prime}$ \\
\hline 21 & Marliéria-MG & Lago Pontes & $-19^{\circ} 39^{\prime} 02,21^{\prime \prime}$ & $-42^{\circ} 34^{\prime} 48,35^{\prime \prime}$ \\
\hline 22 & Planaltina-DF & Lagoa Bonita & $-15^{\circ} 39^{\prime} 00,00^{\prime \prime}$ & $-47^{\circ} 41^{\prime} 00,00^{\prime \prime}$ \\
\hline
\end{tabular}

Com a elaboração do mapa dos 22 estudos palinológicos por estados brasileiros (Figura 2) constatou-se que apenas seis estados de abrangência do bioma Cerrado e o Distrito Federal possuem estudos palinológicos publicados, são eles: Pará, Maranhão, Tocantins, Goiás, Minas Gerais e São Paulo. Destaca-se o estado de Minas Gerais com 11 áreas pesquisadas, representando $50 \%$ das publicações (Figura 3). 
MIRANDA, SILVA

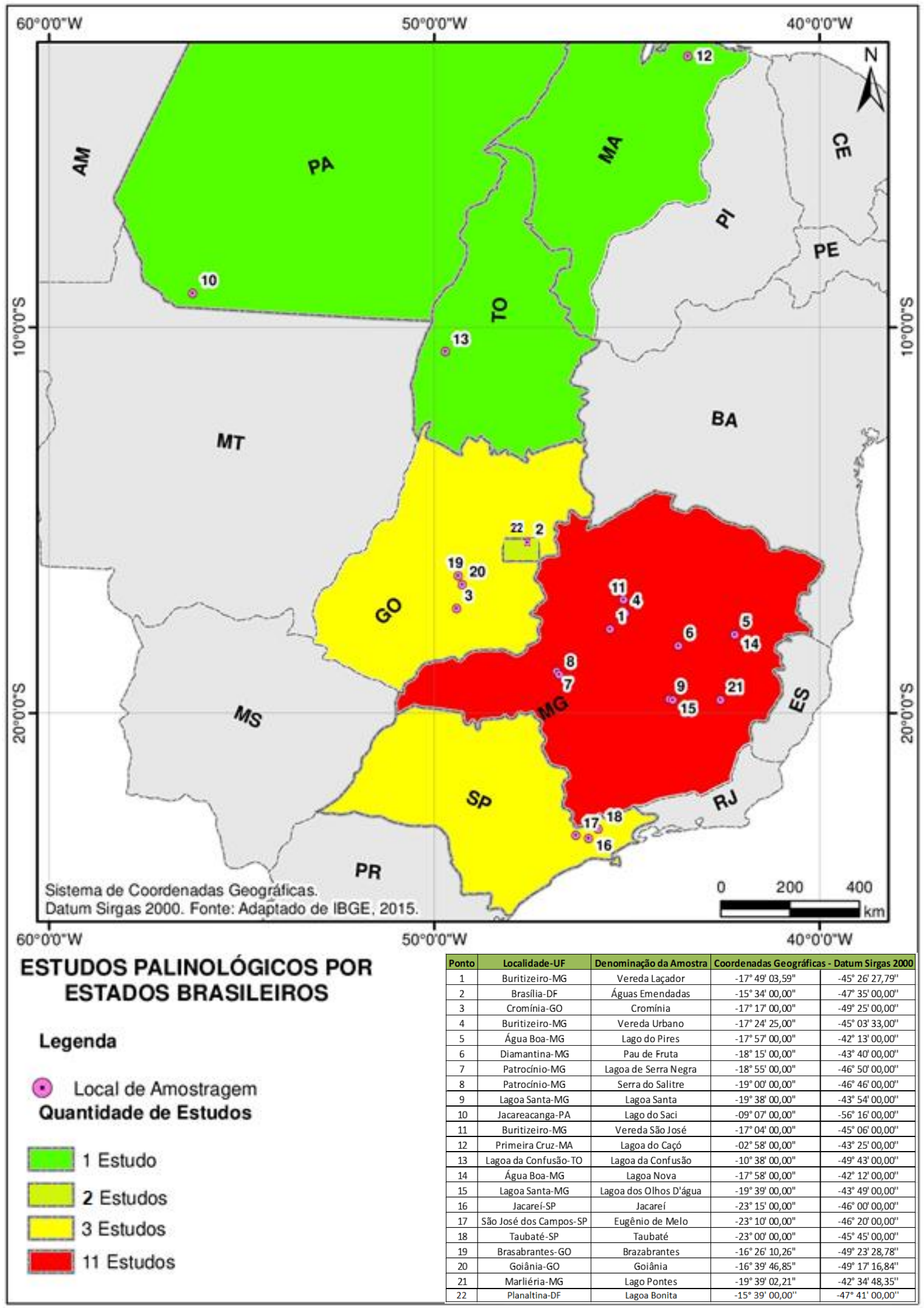

Figura 2: Mapa de localização das amostras palinológicas de diversos autores por estados brasileiros. Fonte: IBGE (2015), com adaptações. 


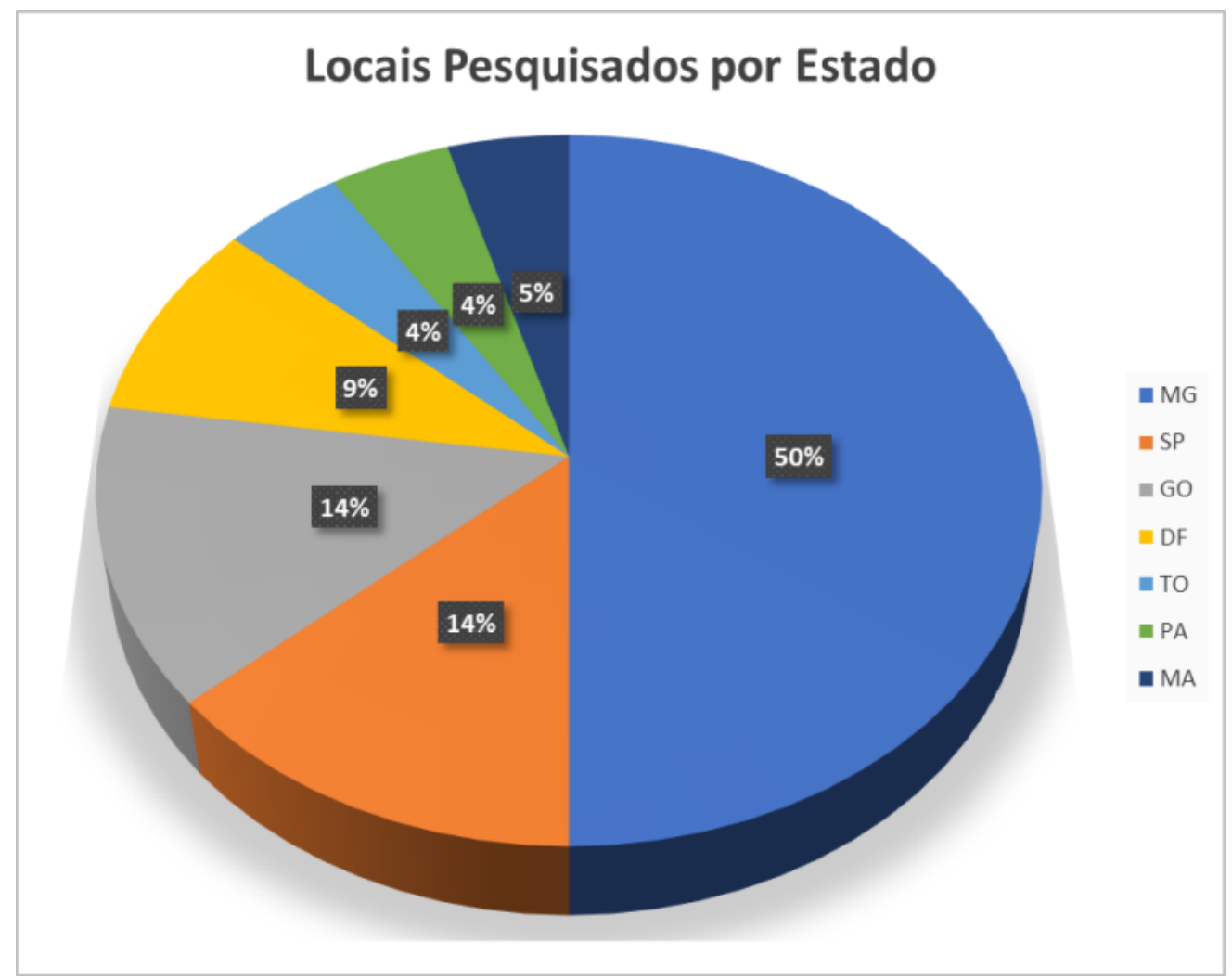

Figura 3: Porcentagem de amostras palinológicas por estados brasileiros.

A Figura 3 demonstra que para uma futura reconstrução do bioma Cerrado no Quaternário serão necessários novos estudos que abranjam os estados de Mato Grosso, Mato Grosso do Sul, Bahia, Piauí, Rondônia, Paraná, Amapá, Roraima, Amazonas e Ceará, pois estes ainda não apresentam estudos palinológicos publicados. Este fato demonstra que maiores esforços de incentivos à pesquisa palinológica necessitam ser realizados na área da educação em instituições de pesquisa do Norte, Nordeste e Sul do país.

Segundo Cassino (2014), existem poucos estudos palinológicos do Quaternário no Cerrado, quando se leva em conta a grande extensão do bioma, fato bem representado pela Figura 4 que ilustra ainda o fato de o bioma Cerrado encontrar-se de forma descontínua em outros biomas como a Amazônia e a Mata Atlântica. 


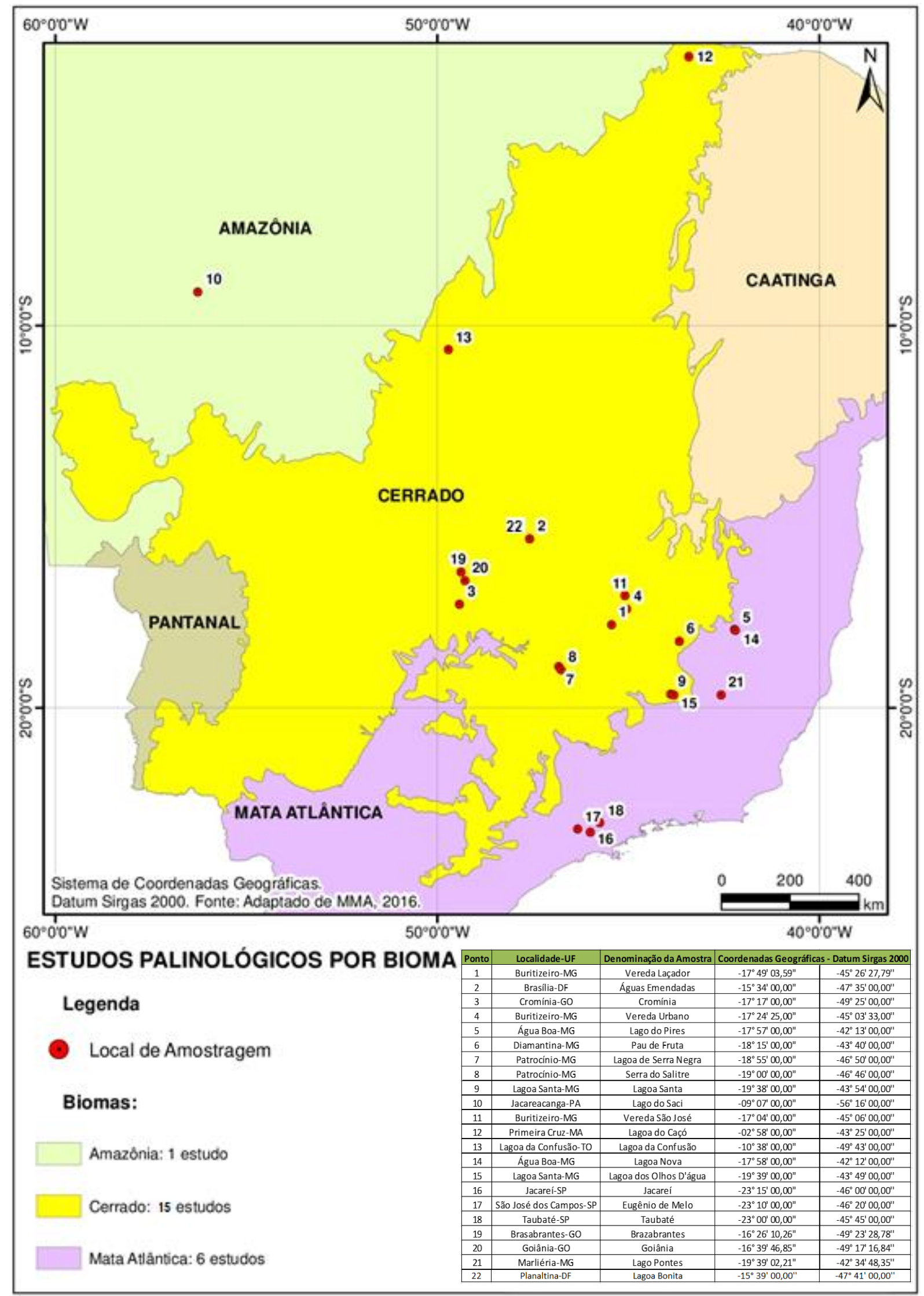

Figura 4: Mapa de estudos palinológicos do Cerrado por bioma contemporâneo. Fonte: MMA (2016), com adaptações.

De acordo com a Figura 5, os locais com clima tipo Aw de Köppen (2007) para o bioma Cerrado são os que mais apresentam publicações sobre palinologia. 
MIRANDA, SILVA

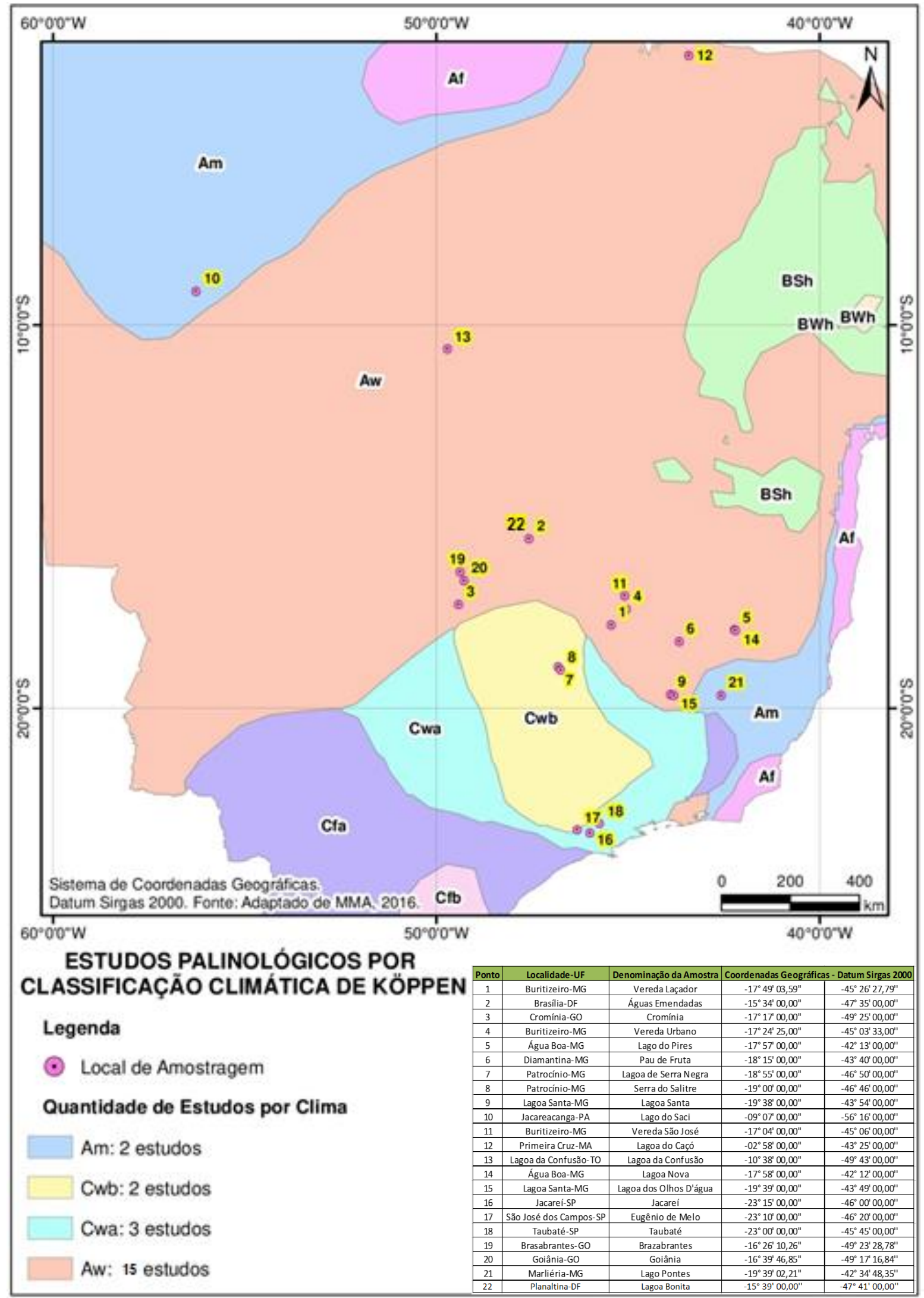

Figura 5: Estudos palinológicos do Cerrado por clima contemporâneo. Fonte: MMA (2016), com adaptações.

Os estudos em clima Aw (tropical com estação seca no inverno) de Köppen (2007) representam 68\% do total de estudos publicados no bioma (Figura 6). 


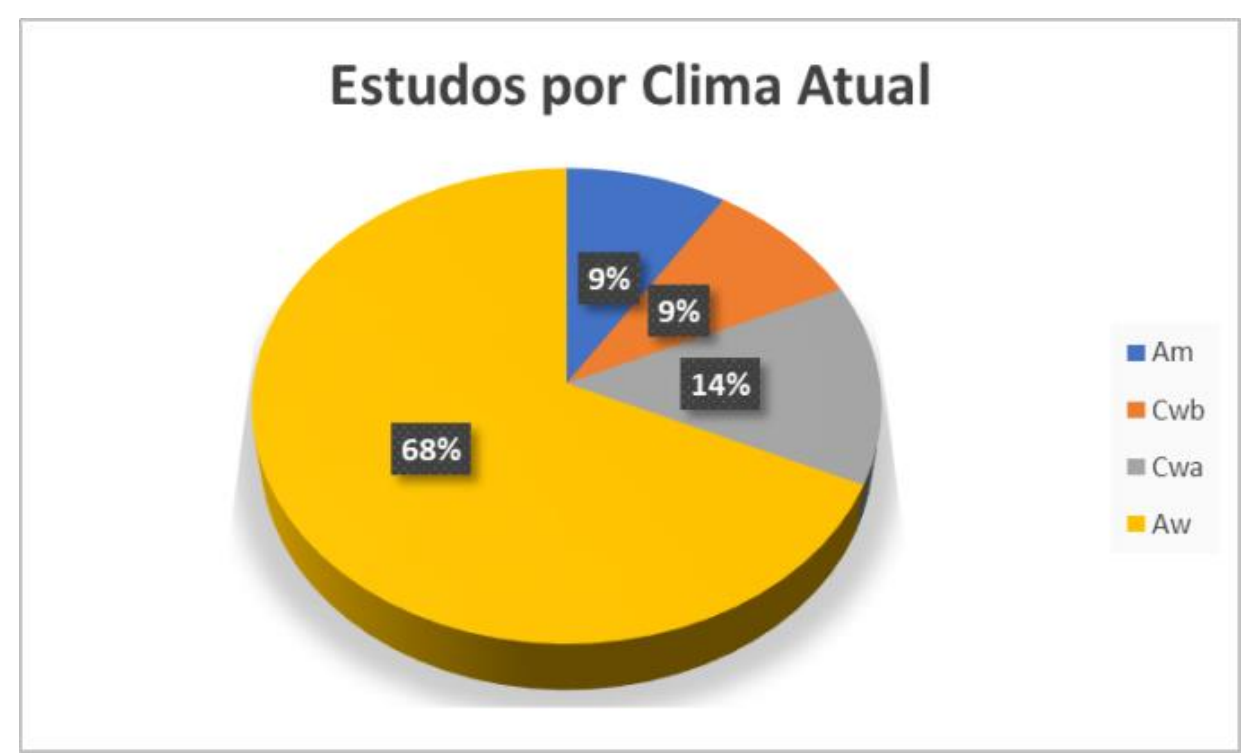

Figura 6: Gráfico de estudos palinológicos no Cerrado por clima contemporâneo.

O Clima Aw possui maior predominância no bioma, mas para uma futura reconstrução do bioma Cerrado no Quaternário serão necessários novos estudos palinológicos que abranjam também os climas Cfa (temperado quente úmido) e BSh (seco com chuvas de inverno e quente), que ainda demonstram-se sem publicações palinológicas.

Já as regiões hidrográficas com maiores números de publicações (Figura 7) correspondem à região hidrográfica do Paraná, São Francisco e Atlântico Leste, respectivamente. Já as regiões hidrográficas mais a Norte e Nordeste (Amazonas, Tocantins e Atlântico-Trecho Norte/Nordeste) apresentam poucos estudos palinológicos publicados, fato que reforça a ideia da necessidade de maiores incentivos à pesquisa palinológica nas regiões Norte e Nordeste. 


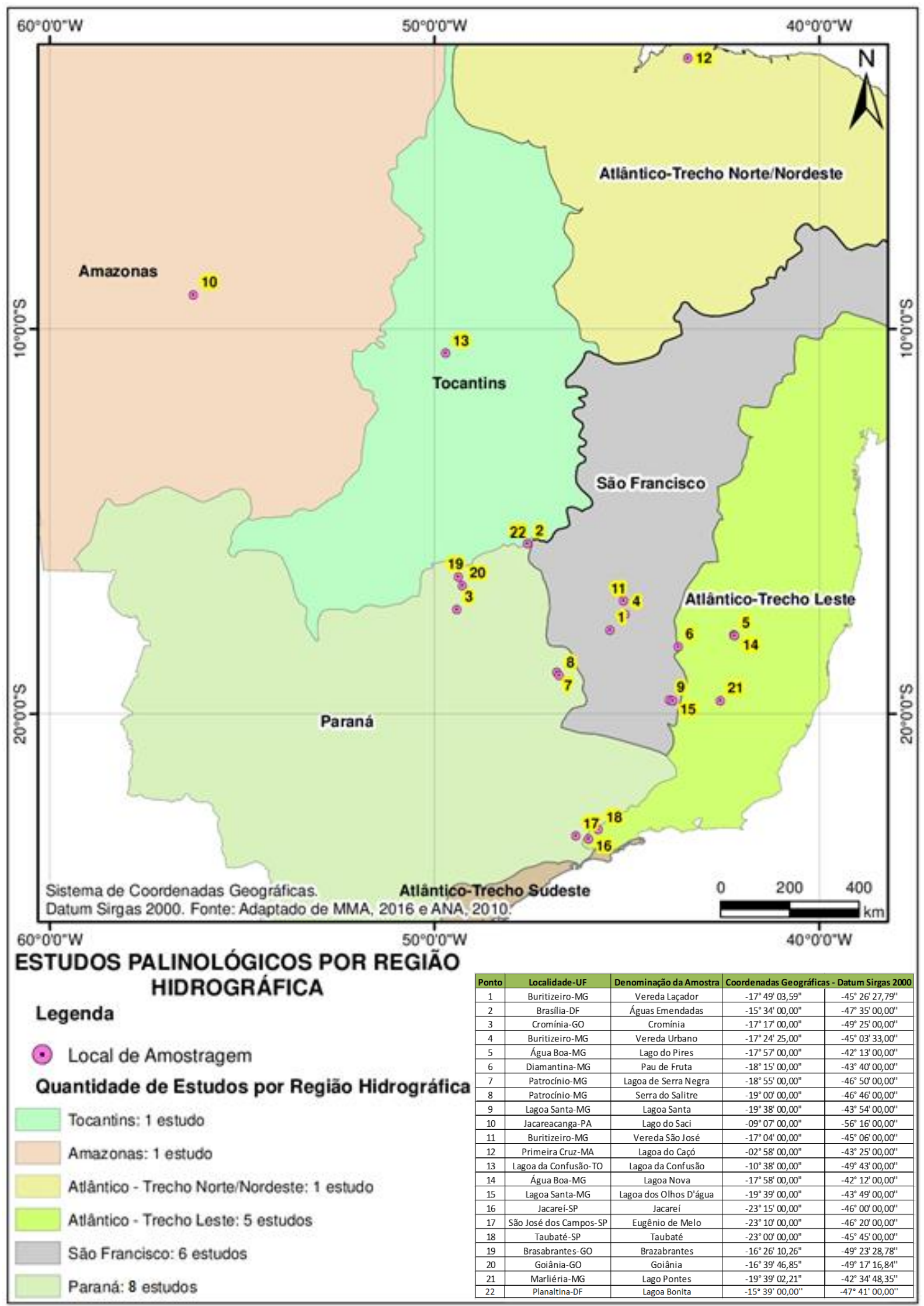

Figura 7: Estudos palinológicos do Cerrado por região hidrográfica. Fonte: MMA (2016) e ANA (2010), com adaptações.

As publicações na região hidrográfica do Paraná correspondem a $36 \%$ do total, São Francisco 27\% e Atlântico Leste 23\% (Figura 8). 


\section{Estudos por Região Hidrográfica}

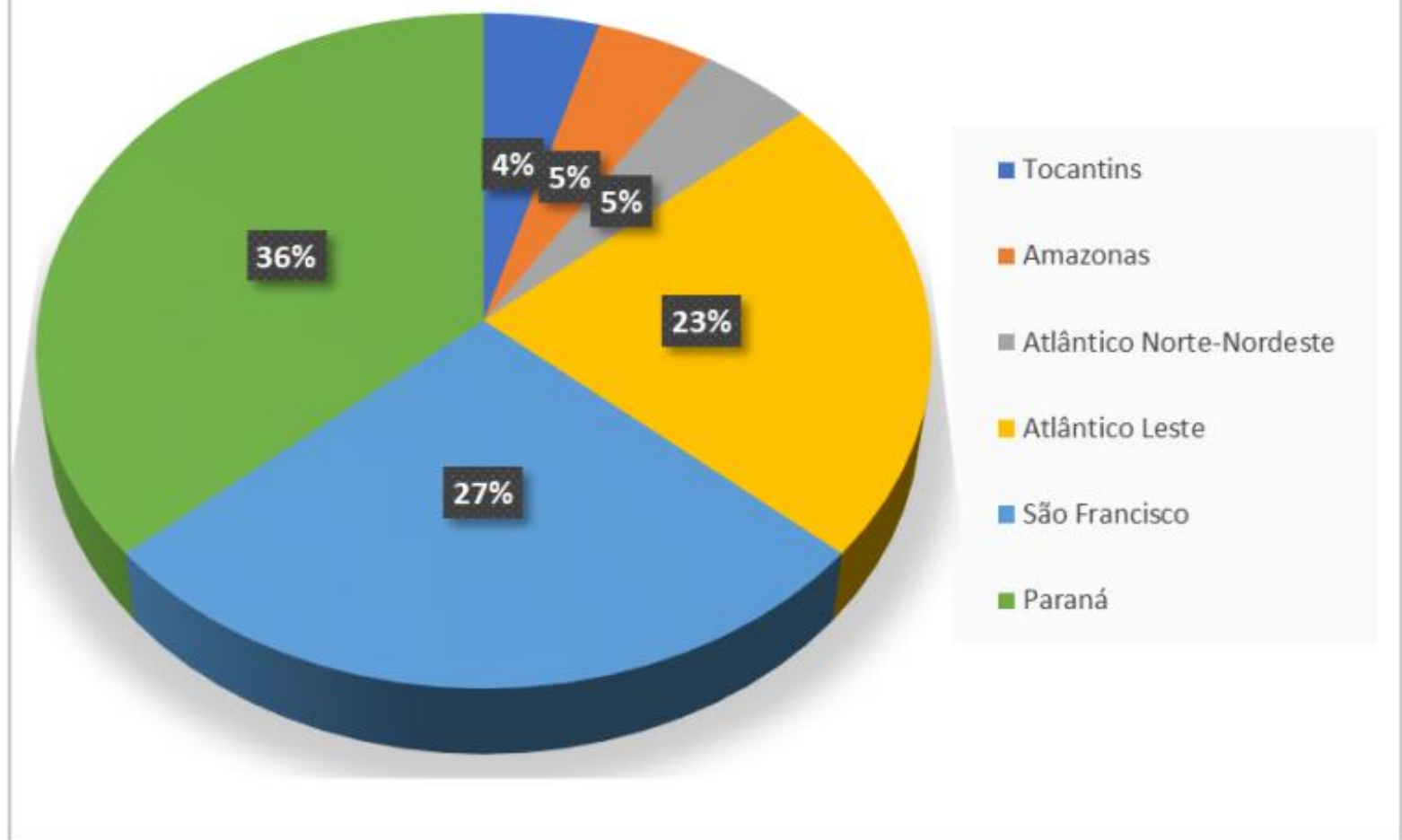

Figura 8: Gráfico de estudos palinológicos do Cerrado por região hidrográfica.

\section{Considerações Finais}

Pelo fato de as fitofisionomias do bioma Cerrado variarem de acordo com os aspectos fisiográficos (latitude, clima, geomorfologia, hidrografia, pedologia e geologia) e com influências de processos de antropização, as modificações fitofisionômicas do Cerrado ao longo do Quaternário não são iguais, homogêneas e sincrônicas para todas as áreas de sítio arqueológico no bioma.

As oscilações climáticas quaternárias impactaram diretamente os recursos vegetais e animais disponíveis às populações humanas pré-históricas, retraindo ou expandindo áreas de matas e campos, causando oscilações no nível do mar, modificando diversos habitats, permitindo ou forçando migrações, adaptações biológicas e culturais. Por intermédio de análises palinológicas de amostras coletadas em sedimentos do Quaternário é possível à remontagem de cenários paleoambientais. Portanto, é de suma importância para a arqueologia tomar conhecimento dos estudos de palinologia que evidenciam mudanças constantes no clima e na vegetação no decorrer do Pleistoceno tardio e do Holoceno. 
Conclui-se que são de suma importância os dados cartográficos disponibilizados, os incentivos à pesquisa e à inovação tecnológica e a reciprocidade de pesquisadores. Verificou-se nos estudos levantados que há aproximação de ciências distintas como a Geologia, Arqueologia, Paleontologia e a Biologia para a solução de problemas específicos em comum e que os respectivos autores possuem diferentes formações intelectuais. Portanto, ressalta-se o caráter multidisciplinar dos estudos levantados, uma vez que permitem a integração do conhecimento e a justaposição dos dados. Estes são complementares a nível regional, corroboram e cooperam comumente para a reconstituição do bioma cerrado durante o Quaternário tardio, fato que permite o enriquecimento mútuo das ciências envolvidas.

Esta pesquisa localizou e registrou cartograficamente áreas de pesquisas palinológicas de sedimentos quaternários no bioma Cerrado, contribuindo para o avanço do conhecimento. Portanto, conclui-se que esta dissertação é um importante subsídio para estudos geológicos, arqueológicos, paleontológicos, biológicos, entre outros, uma vez que o estudo do bioma é comum às ciências supracitadas.

As publicações científicas são de suma importância para a propagação, globalização e evolução do conhecimento científico e a cienciometria, por meio de dados quantitativos, mostrou-se uma ciência adequada para a identificação das lacunas existentes em estudos palinológicos no bioma Cerrado. Porém, constatouse através do estudo cienciométrico que existem poucos estudos palinológicos publicados no Cerrado e de forma descontínua. A oscilação e descontinuidade de publicações sugere que maiores esforços de incentivo à pesquisa necessitam ser realizados na área da educação brasileira (ciência e pesquisa), especialmente em instituições que realizam estudos palinológicos.

Constatou-se que dos estados de abrangência do bioma Cerrado, apenas seis estados possuem estudos palinológicos publicados, destacando-se o estado de Minas Gerais com 11 áreas pesquisadas, representando 52\% das publicações. Maiores esforços de incentivos à pesquisa palinológica necessitam ser realizados na área da educação em instituições de pesquisa do Norte, Nordeste e Sul do país.

Os maiores números de publicações de estudos palinológicos compreendem locais de clima contemporâneo tipo Aw de Köppen no bioma Cerrado, representando $66,67 \%$ do total de estudos publicados, isto se dá devido ao fato que o clima Aw contemporâneo possui maior predominância no bioma. Para reconstituição do clima do bioma durante o Quaternário serão necessários novos estudos palinológicos que 
abranjam regiões de Cerrado com clima Cfa e BSh, pois estes ainda não compreendem publicações palinológicas.

As regiões hidrográficas com maiores números de publicações palinológicas correspondem à região hidrográfica do Paraná, São Francisco e Atlântico Leste respectivamente. As publicações na região hidrográfica do Paraná correspondem a 33,33\% do total, São Francisco 28,57 \% e Atlântico Leste 23,81\%. Já as regiões hidrográficas mais a Norte e Nordeste (Amazonas, Tocantins e Atlântico-Trecho Norte/Nordeste) apresentam poucos estudos palinológicos publicados, fato que reforça a ideia da necessidade de maiores incentivos à pesquisa palinológica nas regiões Norte e Nordeste.

\section{REFERÊNCIAS}

ABSY, M. L; SERVANT, M; ABSY, M. L. A história do clima e da vegetação pelo estudo do pólen. Ciência Hoje, São Paulo, v. 16, p. 26-30, 1993.

ANA, Agência Nacional de Águas. Região Hidrográfica do Tocantins-Araguaia. Brasil, 2010. Disponível em: <http://metadados.ana.gov.br/geonetwork/srv/pt/main.home>. Acesso em: 15 de jul. de 2016.

ARENCIBIA JORGE, R.; DE MOYA ANEGON, F. La evaluación de la investigación científica: una aproximación teórica desde la cienciometría. ACIMED [online]. vol.17, n.4, p. 1-27, 2008. Disponível em: <http://scielo.sld.cu/scielo.php?script=sci_isoref\&pid=S102494352008000400004\&lng=en\&tlng=es >. Acesso em: 05 jul. de 2016.

BARBERI, M. História Ecológica de Águas Emendadas/DF. Seminário Pesquisa em Unidades de Conservação. Brasília, Anais, SEMATEC, 153-170p, 1998.

BARBERI, M. Mudanças Paleoambientais na Região dos Cerrados do Planalto Central Durante o Quaternário Tardio: O Estudo da Lagoa Bonita, DF. São Paulo, 210 p. Tese de Doutoramento - Instituto de Geociências, Universidade de São Paulo, 2001.

BARBERI, M. Paleovegetação e Paleoclima no Quaternário Tardio da Vereda de Águas Emendadas. Programa de Pós-Graduação em Geologia, Universidade de Brasília, Dissertação de Mestrado, 110 p, 1994.

BARBERI, M.; SALGADO-LABOURIAU, M.L. \& SUGUIO, K. Paleovegetation and paleoclimate of "Vereda de Águas Emendadas", Central Brazil. Journal of South American Earth Sciences, 13:241-254. doi:10.1016/S0895-9811(00)00022-5, 2000.

BARTLETT, A. S; BARGHOORN, E. S; BERGER, R. Fossil maize from Panama. Science, Washington, DC, v. 165, p. 389-390, 1969.

BEHLING, $H$. Late quaternary vegetational and climatic changes in Brazil. Review of Palaeobatany and Palynology, Amsterdam, v. 99, p. 143-156, 1998.

$\mathrm{BICHO}$, N. F. Manual de Arqueologia Pré-Histórica. Lisboa, 2006. Disponível em: <https://leiaufsc.files.wordpress.com/2017/03/bicho-n-f-2006-manual-de-arqueologia-prc3a9histc3b3rica.pdf>. Acesso em: 24 jun. de 2017.

BRAIDWOOD, R. J., 1907. Homens Pré-Históricos. Brasília, Editora Universidade de Brasília, 1985.

CASSINO, R. F. Reconstituição paleoambiental da região dos cerrados do norte de Minas Gerais baseada na análise palinológica de sedimentos de veredas e na comparação com conjuntos polínicos atuais. Brasília, 2014. Disponível em: <http://repositorio.unb.br/handle/10482/17117>. Acesso em: 19 abr. de 2016. CASSINO, R. F.; MARTINHO, C. T.; CAMINHA, S. Diversidade de grãos de pólen das principais fitofisionomias do cerrado e implicações paleoambientais. Journal of Geoscience, v. 9, n. 1, p. 4-29, 2016. Disponível em: < 
http://revistas.unisinos.br/index.php/gaea/article/view/gaea.2016.91.01/5351>. Acesso em: 19 abr. de 2016.

CASSINO, R. F.; MEYER, K. E. B. Reconstituição Paleoambiental Do Chapadão Dos Gerais (Quaternário Tardio) A Partir Da Análise Palinológica Da Vereda Laçador, Minas Gerais, Brasil. Sociedade Brasileira de Paleontologia, 2013. Disponível em: < http://www.sbpbrasil.org/revista/edicoes/16_1/10_Cassino_\&_Meyer.pdf>. Acesso em: 19 abr. de 2016.

DE MIRANDA CHAVES, S. A. Estudo palinológico de coprólitos pré-históricos Holocenos coletados na Toca do Boqueirão do Sítio da Pedra Furada. Contribuições paleoetnológicas, paleoclimáticas e paleoambientais para a região sudeste do Piauí-Brasil. Revista do Museu de Arqueologia e Etnologia, n. 10, p. 103-120, 2000.

DO CARMO, F.; BARBERI, M.; RUBIN, J. C. R. de. Análise palinológica de sedimentos do Quaternário Tardio, a partir de 44.000 anos AP, na região centro-sul do Estado de Goiás, Brasil. IX ABEQUA, Recife. Anais... Recife, v. 1, 2003.

FERRAZ-VICENTINI, K. R. C. F. Análise Palinológica de uma Vereda em Cromínia, GO. Programa de Pós-Graduação em Geologia, Universidade de Brasília: UnB, Dissertação de Mestrado, 87 p, 1993.

FERRAZ-VICENTINI, K. R. C. F. História do fogo no cerrado: uma análise palinológica. Brasília, Tese de Doutorado - Instituto de Ciências Biológicas, Universidade de Brasília, 208p., 1999.

FERRAZ-VICENTINI, K. R. C. F.; SALGADO-LABOURIAU, M. L. Palynological analysis of a palm swamp in central Brazil. Journal of South American Earth Sciences, v. 9, n. 3-4, p. 207-219, 1996. Disponível em: <

https://www.sciencedirect.com/science/article/pii/0895981196000077> Acesso em: 15 de jul. 2016.

FONTES, D.; BARROS, M. A. de; MARTINS, G. S.; RODRIGUES, R. A; CORDEIRO, R. C.; SIFEDDINE, A.; TURCQ, B.; SEOANE, J. C. S. Ocorrência do Pólen de Mauritia L.F. (Arecaceae) e Suas Implicações Paleoclimáticas Desde os Últimos 7.000 Anos em Sedimentos Lacustres da Região de Itaituba, Sul do Pará, Brasil. Abequa, 2011. Disponível em:<http://www.abequa.org.br/trabalhos/Resumo_Abequa_2011_fina.pdf>. Acesso em: 01 de out. de 2016.

GARCIA, M. J. Palinologia de turfeiras quaternárias do médio vale do rio Paraíba do Sul, Estado de São Paulo. Tese de Doutorado. Universidade de São Paulo, 1994. GOSLING, W.; MAYLE, F. E.; TATE, N. J.; KILLEEN, T. J. Differentiation between Neotropical rainforest, dry forest, and savannah ecosystems by their modern pollen spectra and implications for the fossil pollen record. Review of Palaeobotany and Palynology, 153: 70-85, 2009.

GOWLETT, J. Arqueologia das Primeiras Culturas. Barcelona, 2007.

HORÁK, I. Relações pedológicas, isotópicas e palinológicas na reconstrução paleoambiental da turfeira da Área de Proteção Especial (APE) Pau de Fruta, Serra do Espinhaço Meridional. Escola Superior de Agricultura 'Luiz de Queiroz', Universidade de São Paulo, Dissertação de Mestrado, 203p, 2009.

IBGE, Instituto Brasileiro de Geografia e Estatística. Mapas de Biomas e Vegetação. 2015. Disponível em:

<http://www.ibge.gov.br/home/presidencia/noticias/21052004biomashtml.shtm>. Acesso em: 07 jul. de 2015.

IBGE, Instituto Brasileiro de Geografia e Estatística. Mapas Político-Administrativos. 2015. Disponível em: <http://mapas.ibge.gov.br/politico-administrativo>. Acesso em: 01 de out. de 2015.

KÖPPEN, W. P. Köppen classification. Climate, 2007. Disponível em: <http://www.meteorologyclimate.com/koppenclassification.htm>. Acesso em: 01 de out. de 2015.

LEDRU, M. P. Late Quaternary History and Evolution of the Cerrados as Revealed by Palynological Records. In: Oliveira, P. S., Marquis, R. S. (Eds.). Ecology and Natural History of a Neotropical savanna: The Cerrados of Brazil. The University of Columbia Press, pp. 33-50, 2002. 
LEDRU, M. P.; BRAGA, P. I. S.; SOUBIÈS, F.; FOURNIER, M.; MARTIN, L.; SUGUIO, K. \& TURCQ, B. The last 50,000 years in the Neotropics (Southern Brazil): evolution of vegetation and climate. Palaeogeography, Palaeoclimatology, Palaeoecology, 123:239-257. doi:10.1016/0031-0182(96)00105-8, 1996.

LORENTE, F. L.; MEYER, K. E. B. Palinomorfos da vereda da Fazenda Urbano, município de Buritizeiro, Minas Gerais, Brasil. Iheringia, Série Botânica, v. 65, n. 2, p. 133-169, 2010. Disponível em: < http://www.academia.edu/download/40773836/2010_-_Lorente___Meyer__palinomorfos.pdf>. Acesso em: 15 de jul. de 2016.

LORENTE, F. L.; MEYER, K. E. B.; HORN, A. H. Análise Palinológica da Vereda da Fazenda Urbano, Município de Buritizeiro, Minas Gerais, Brasil. Revista Geonomos, 2010. Disponível em: <http://general.igc.ufmg.br/geonomos/PDFs/2.03_Lorenteetal_57_72.pdf>. Acesso em: 01 de out. de 2016.

MACIAS-CHAPULA, C. A. O papel da informetria e da cienciometria e sua perspectiva nacional e internacional. Ciência da informação, v. 27, n. 2, 1998.

MANNONI, T.; GUIANNICHEDDA, E. Arqueología: Materiais, objetos y Producciones. Grupo Planeta (GBS), Barcelona, 2007.

MARTÍNEZ, V. M. F. Pré-História. El Largo Camino de la Humanidad. Madrid. Alianza Editorial, p 304, 2007.

MELATTI, J. C. Índios do Brasil. São Paulo, Editora da Universidade de São Paulo, 2007. MILLER, F. S. Arqueologia e Etnografia. UFRN, São Paulo, 2009.

MINGERS, J.; LEYDESDORFF, L. A review of theory and practice in scientometrics. European Journal of Operational Research, v. 246, p. 1 -19, 2015. Disponível em: $<$ http://ac.elscdn.com.ez49.periodicos.capes.gov.br/S037722171500274X/1-s2.0S037722171500274X-main.pdf?_tid=ce6eacf0-2339-11e5-8f1a-

00000aab0f02\&acdnat $=1436116868 \_$bcc4136359cbacda7598c55d8fed4d44>. Acesso em: 05 jul. de 2015.

MMA, Ministério do Meio Ambiente. Download de Dados Geográficos. Disponível em: < http://mapas.mma.gov.br/i3geo/datadownload.htm>. Acesso em: 01 de out. de 2016.

MORAES, Roque. Análise de conteúdo. Educação, v. 22, n. 37, p. 7-32, 1999.

NEVES, E. G. Existe algo que se possa chamar de "arqueologia brasileira"?. Estudos avançados, v. 29, n. 83, p. 07-17, 2015.

NEVES, E. G. Os Índios Antes de Cabral: Arqueologia e História Indígena no Brasil. A temática indígena na escola. Brasília: MEC/MARI/UNESCO, p. 171-192, 1995.

PARIZZI, M. G.; SALGADO-LABOURIAU, M. L.; KOHLER, C. H. Genesis and environmental history of Lagoa Santa, SE, Brazil. The Holocene, 8:311-321.

doi:10.1191/095968398670195708, 1998.

PIMENTA, J. Desenvolvimento sustentável e povos indígenas: os paradoxos de um exemplo amazônico. Anuário Antropológico, v. 2003, p. 115-150, 2004. Disponível em:

$<$ https://aprender.ead.unb.br/pluginfile.php/202278/mod_resource/content/1/10-

\%20Desenvolvimento\%20sustent\%C3\%A1 vel\%20e\%20povos\%20ind\%C3\%ADgenas\%20\% 28Pimenta\%29.pdf> Acesso em: 01 de nov. de 2016.

PROUS, A. Arqueologia Brasileira. Brasília, DF: Editora Universidade de Brasília, 1992.

PROUS, A. O povoamento da América visto do Brasil: uma perspectiva crítica. Revista USP, n. 34, p. 8-21, 1997.

RIBEIRO, M. de S. L.; BARBERI, M. Análise Palinológica: fundamentos e perspectivas na pesquisa arqueológica. Habitus, v. 3, n. 2, p. 261-290, 2005.

RIBEIRO, M. de S. L.; BARBERI, M.; RUBIN, J. C. R. de. Reconstrução da Composição Florística no Decorrer dos Últimos 32.000 Anos AP em Áreas de Cerrados da Bacia Hidrográfica do Rio Meia Ponte, Goiás, Brasil. In: Congresso da Associação Brasileira de Estudos do Quaternário. 2003.

SALGADO-LABOURIAU, M. L. Contribuição à palinologia dos cerrados. Rio de Janeiro:

Academia Brasileira de Ciências, 1973. 291 p. 1984 Reconstrucion de los Ambientes Atraves de los Granos de Polen.

Investigacion y Ciencia (Spanish edition of the Scientific American), 96 septiembre, 3:6-17. SALGADO-LABOURIAU, M. L.; BARBERI, M.; FERRAZ-VICENTINI, K. R. A dry climatic event during the Late Quaternary of tropical Brazil. Review of Paleobot. and Palynology, 99: 115-129, 1998. 
SALGADO-LABOURIAU, M. L.; CASSETI, V.; FERRAZ-VICENTINI, K. R.; MARTIN, L.; SOUBIÉS, F.; SUGUIO, K.; TURCQ, B. Late Quaternary vegetational and climatic changes in cerrado and palm swamp from Central Brazil. Paleogeography, Paleoclimatology, Paleoecology, 128: 215-226, 1997.

SCHMITZ, P. I. Caçadores Coletores do Brasil Central. In: Pré-história da Terra Brasilis. Rio de Janeiro: Editora UFRJ, p. 75-88, 1999.

SILVA, A. L. Da. Mitos e cosmologias indígenas no Brasil: breve introdução. In: Índios no Brasil. Grupioni, L. D. B. (org.) Índios no Brasil. Brasília: Ministério da Educação e do Desporto, p. 75-82, 1992.

SILVA, C. E. M. Ordenamento Territorial no Cerrado brasileiro: da fronteira monocultora a modelos baseados na sociobiodiversidade. Desenvolvimento e meio ambiente, v. 19, 2009.

SILVA, F. A. As atividades econômicas das populações indígenas amazônicas e a formação das terras pretas: O exemplo dos Asurini do Xingu. As terras pretas de índio da

Amazônia: sua caracterização e uso deste conhecimento na criação de novas áreas. Embrapa. Manaus, Brasil, p. 54-61, 2009. Disponível em:

<http://www.biochar.org/joomla/images/stories/Cap_4_Fabiola.pdf>. Acesso em: 02 de nov. de 2016.

SPINAK, E. Indicadores cienciometricos. Ciência da Informação. Brasília, v. 27, n. 2, p. 141

- 148, 1998. Disponível em: <http://www.scielo.br/scielo.php?script=sci_arttext\&pid=S0100$19651998000200006 \&$ Ing=pt\&nrm=iso >. Acesso em: 05 jul. de 2015

STREHL, L.; SANTOS, C. A. dos. Indicadores de qualidade da atividade científica. Ciência Hoje, Rio de Janeiro, v. 31, n. 186, p. 34-39, 2002. Disponível em:

<http://www.if.ufrgs.br/ cas/FI_CH.pdf>. Acesso em: 05 jul. de 2015.

TASSINARI, A. M. I. Sociedades Indígenas: Introdução ao Tema da Diversidade Cultural.

In: Temática Indígena Na Escola: Novos Subsídios para Professores de Primeiro e Segundo Graus. v. 1, p. 445-479, 1995.

TOLEDO, M. C. M.; FAIRCHILD, T. R.; TEIXEIRA, W. Decifrando a terra. São Paulo: IBEP, v. 98, 2009.

VAN DER HAMMEN, T. Palaeoecology of the Neotropics: an overview of the state of affairs. Boletim IG-USP, 8:35-55, 1991.

VANTI, N. A. P. Da bibliometria à webometria: uma exploração conceitual dos mecanismos utilizados para medir o registro da informação e a difusão do conhecimento. Ciência da informação, Brasília, v. 31, n. 2, p. 152-162, 2002. Disponível em: < http://www.scielo.br/pdf/ci/v31n2/12918.pdf>. Acesso em: 05 jul. de 2015.

VITA-FINZI, C.; HIGGS E. S., Prehistoric Economy in the Mount Carmel Area of Palestine: Site Catchment Analysis. Proceedings Society London, 1970, 1-37.

\section{NOTAS DE AUTOR}

\section{CONTRIBUIÇÃO DE AUTORIA}

Maria Carolina Cruz Miranda - Concepção, levantamento de dados, análise de dados, elaboração do manuscrito,
participação ativa da discussão dos resultados, revisão e aprovação da versão final do trabalho.
Gabriela Paola Aguiar Silva- Elaboração do manuscrito, análise de dados, discussão dos resultados, revisão e aprovação
da versão final do trabalho.

FINANCIAMENTO

Não se aplica

CONSENTIMENTO DE USO DE IMAGEM

Não se aplica

APROVAÇÃO DE COMITÊ DE ÉTICA EM PESQUISA

Não se aplica

CONFLITO DE INTERESSES

Não há 
LICENÇA DE USO

Este artigo está licenciado sob a Licença Creative Commons CC-BY. Com essa licença você pode compartilhar, adaptar, criar para qualquer fim, desde que atribua a autoria da obra.

\section{HISTÓRICO}

Recebido em: 27-09-2018

Aprovado em: 08-05-2019 